\title{
Espacio público
}

Elke Schlack Profesora, Escuela de Arquitectura, Pontificia Universidad Católica de Chile y Universidad Nacional Andrés Bello

El actual prestigio de lo privado, la políticamente correcta pero devaluada condición pública y la ausencia de matices en las distinciones entre ambos urgen la definición de un código que asegure la continuidad de lo público en la ciudad. Bernardo Secchi decía que el espacio público es donde "se está en público"; ¿las ordenanzas recogen esta afirmación?

Desde la perspectiva legal urbana ${ }^{1}$, el territorio está compuesto por calles y plazas de uso público y lotes con edificaciones de uso privado. La ley es tajante.

La Ordenanza General de Urbanismo y Construcciones define el espacio público como Bien Nacional de Uso Público². Esta definición muestra explícitamente una interdependencia entre dos aspectos que hoy son cada vez más autónomos: el de propiedad y el de uso. En primera instancia, el derecho vincula al espacio público con una propiedad pública (Bien Nacional), es decir, con el dominio del Estado. Esto implica que su regulación se rige según derecho público y que su uso está regulado por el Estado. En segunda instancia, se desprende de la definición legal que el uso del espacio público está en directa relación con su estatus de propiedad: la ley no contempla que espacios de otra naturaleza puedan ser usados públicamente ${ }^{3}$

Pero sabemos que hoy la vida pública transcurre en espacios que no son ni estatales ni públicos: en verano preferimos los pasajes techados que cruzan de un lado a otro los edificios, compramos el diario en el quiosco del estacionamiento subterráneo y regalos de Navidad en las galerías del Metro; es más, algunos prefieren usar las áreas verdes de un condominio en vez de ir a la plaza del barrio. Y a pesar de que todos esos lugares tienen a lo menos un dueño, nos movemos en ellos como si estuviéramos en la calle; para la arquitectura, estos lugares son parte del espacio público (Selle, 2001), aunque hay quien prefiere llamarlos espacios colectivos (Solà -Morales, 1994 y Gausa, 2003).

Los arquitectos sabemos mejor que nadie que la realidad territorial no es tan tajante como la presenta la normativa. La arquitectura caracteriza como públicos todos aquellos espacios que son accesibles públicamente, tal como lo ejemplifica la Nuova Topografía di Roma propuesta por Gianbattista Nolli en 1784. Para nosotros lo público y lo privado son dos polos; entre uno y otro extremo, reconocemos una serie de espacios intermedios. Lo que nosotros vemos son transiciones. $Y$ en esto estamos de acuerdo con el urbanismo, que considera que son esencialmente estas transiciones entre estos polos las que constituyen la particular calidad de las secuencias espaciales de la ciudad (Selle, 2001).

La sociología tampoco clasifica el territorio según quién es su dueño, sino de acuerdo a quién lo usa. El sociólogo Max Weber indicó que la condición primitiva del espacio público se remonta a las plazas de la ciudad medieval europea, caracterizadas por su actividad comercial (Weber, 1980). Es aquí donde tuvo lugar la forma primitiva de vida pública (Öffentlichkeit) en el sentido sociológico (Bahrdt, 1969). En la sociología se ha caracterizado la Öffentlichkeit como una situación en la que predomina el anonimato, donde los individuos tienen la libertad de establecer contacto o distanciarse según su voluntad. De esta manera son características del espacio público una integración parcial, un sistema social abierto y la interacción entre desconocidos (Bahrdt, 1969). En ese sentido, hasta hoy se sostiene que la ciudad es una forma de asentamiento que hace posible el encuen-
The actual prestige of the private sector, the politically correct but devalued public sector, and the absence of shades in the distinctions between both makes the definition of a code urgent that will ensure the continuity of public spaces in the city. Bernardo Secchi has said that public space is where "one is in public." Do the ordinances reflect this?

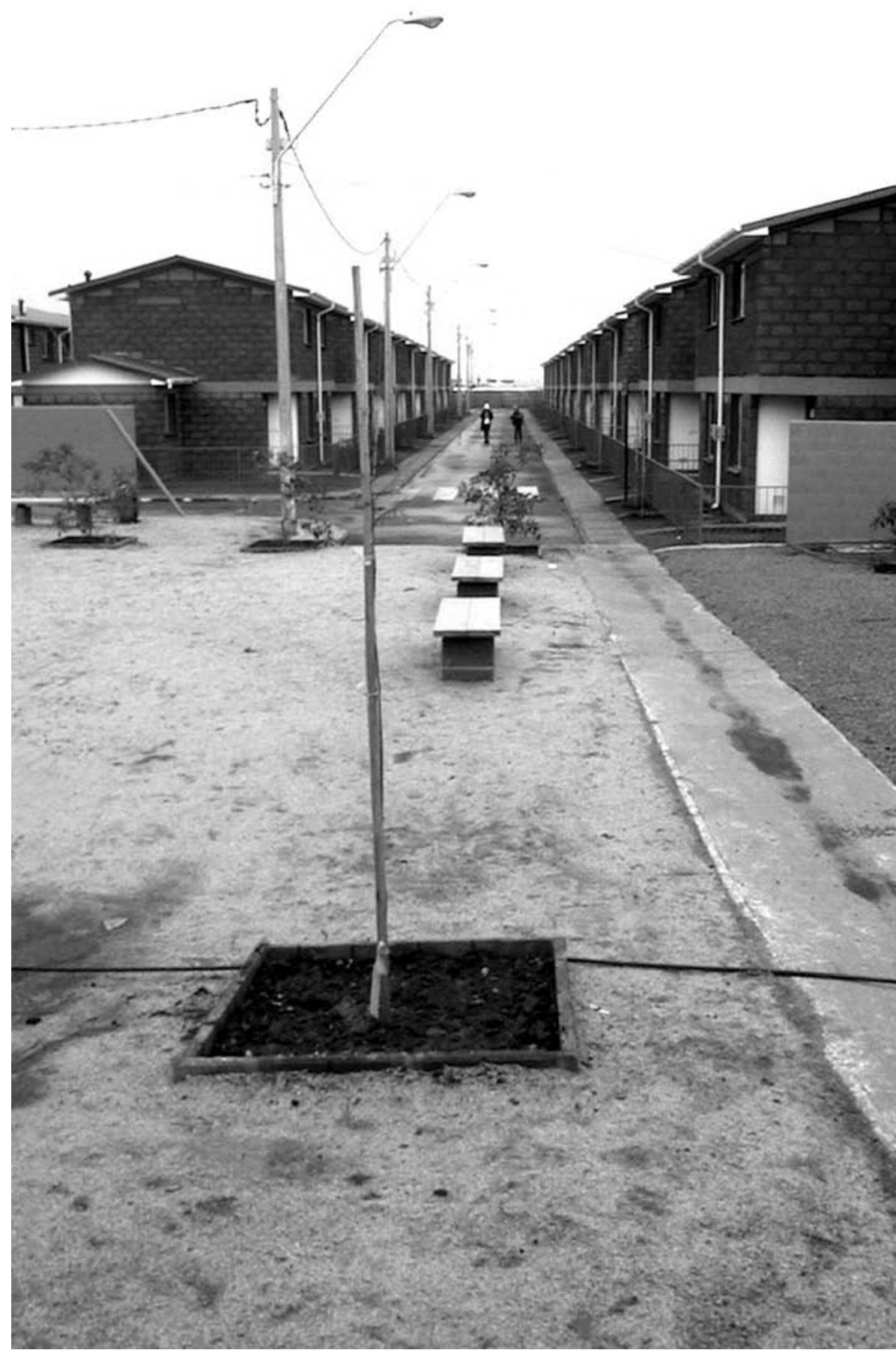

01 Loteo de vivienda social, La Capilla, Puente Alto. Fotografía de la autora. 
' Con legislación urbana me refiero esencialmente a la Ley y Ordenanza General de Urbanismo y Construcciones, Ordenanzas Locales de Urbanismo y Construc ciones, así como Ordenanzas de Planos Reguladores.

Art. 1.1.2 Definiciones de Ordenanza General de Urbanismo y Construcciones (DS № 20.192 de 2006). Ver además: Título de Chile.

3 Título 3, Código Civil de la República de Chile. Artículo 64 del Decreto con Fuerza de Ley acerca de la afectación los Bienes

\section{№ 1939 de 1977), artículos 59 y 70 de la Ley General de Urbanismo y Construcciones (Ley № 19.939 de 2004). \\ 4 Revisar la bibliografía de Koda y Krämer acerca del origen del concepto de uso público en el derecho alemán.}

5 Artículo 822 y Título XI completo del Código Civil de la República de Chile.

- Artículo 2 № 6 y artí́culo 3 de la Ley de Copropiedad Inmobiliaria (Ley № 19.537 del 1997). 7 Definición de "Galería: espacio generalmente cubierto, horizontal o en rampa, destinado a la circulación de público, con locales comerciales a uno 0 ambos lados". Art 1.1.2 OGUC Modificado por DS. № 75 de 2001 y por D.S. № 87 de 2004)

${ }^{8}$ Entrevista con el arquitecto Rodrigo Rojas, asesor urbano de la Municipalidad de Providencia en el período de la construcción de la estación de Metro Los Leones. tro entre personas desconocidas (Sennett, 1983); la característica distintiva del espacio público es su grado de accesibilidad o la posibilidad de su uso sin restricciones para cualquier persona. En sentido sociológico, el espacio público es el espacio de uso público (Selle, 2001).

Es por eso que se hace necesario establecer, a nivel de la Ordenanza, categorías que den cuenta de los diferentes grados de accesibilidad y uso público de los espacios.

El derecho no contempla un estatus jurídico apropiado para estos espacios de transición entre lo público y lo privado. Este fenómeno se puede originar en el siguiente hecho: la conceptualización legal de espacio público es propia de una época en que su principal gestor era el Estado. Hoy, la situación ha cambiado y es evidente que se acentúa la acción de actores privados en la creación de espacios para la vida pública. Sin embargo, el derecho urbano aún no conceptualiza como espacios públicos aquellos ubicados en territorio privado, pero cuyo uso es público. En términos jurídicos, tales espacios son privados y su uso se rige según la voluntad del dueño: de esta forma, puede ser restringido a determinadas personas si ellas, por ejemplo, no cumplen con la visión que el propietario tiene del lugar.

Un estatus jurídico adecuado para este tipo de espacios no constituye en absoluto algo nuevo. Desde el pasado feudal existe una figura legal 1lamada servidumbre de tránsito (Kodal, Krämer, 1999). Se trata de la cesión de una franja de territorio privado a un uso común, recurso que originalmente tuvo lugar en caminos muy transitados dentro del territorio feudal, lo cual llevó al correspondiente señor a gravar estos caminos como espacios de uso público. La tuición sobre estos caminos la tenía la autoridad feudal, quien se hacía cargo de mantener orden y seguridad. Al pasar el derecho del espacio público al modelo actual, donde la autoridad es el Estado, el concepto de uso público se vinculó inseparablemente a la propiedad pública ${ }^{4}$.

El desafío actual es crear otros instrumentos jurídicos que permitan otorgar un estatus legal adecuado a estos espacios que están entre lo público y lo privado.

En el ámbito del derecho urbano, en general, es preciso redefinir el concepto espacio público como bien nacional o bien privado de uso público, rompiendo con la hasta ahora indisoluble unión entre uso y propiedad. Cabe hacer notar que en el derecho civil existen figuras legales que concuerdan con este planteamiento; por un lado, existe el ya mencionado concepto de servidumbre de tránsito ${ }^{5}$, y por otro, el concepto bienes de dominio común, definición que la ley de copropiedad inmobiliaria confiere a los espacios comunes de los condominios ${ }^{6}$.

En el ámbito del derecho urbano, particularmente, se requiere que la normativa reconozca más categorías de espacio urbano según el criterio de su uso y accesibilidad. En esa dirección, proponemos tipificar los espacios que ya son parte de nuestra experiencia urbana de la siguiente manera: las calles y plazas de libre acceso como espacios públicos, las galerías comerciales al aire libre que establecen continuidad con la calle como espacios aparentemente públicos, las áreas comunes de los condominios como espacios semipúblicos, etc.

Sin duda será necesario iniciar un debate al respecto y será preciso analizar las prácticas de este tipo existentes en Chile y el extranjero. De relevancia internacional es el caso del Unified Bulk Program en Nueva York, que tipifica los espacios públicos de propiedad privada (privately owned public spaces) según criterios morfológico-espaciales (urban plaza, sidewalk widening, open air concourse, residential plaza, etc.) (Kaiden, 2000) y promueve la creación de espacios de uso público heterogéneos, apropiados a cada situación urbana en particular. También es interesante tener en cuenta la aproximación del gobierno de la ciudad de Berlín, que ha desarrollado un plan estratégico de espacio público: StEP öffentlicher Raum (Dubach y otros, 1999). Este plan tipifica los espacios públicos y sus transiciones considerando que son parte de un sistema de espacios públicos prioritario y no resultante de lo construido, categorizándolos según la identidad espacial de cada uno; establece en lo particular criterios según sus grados de accesibilidad, traspaso, conectividad, espacialidad interna, escala y orientación, entre otros.

En Chile se destaca el caso de la comuna de Providencia, que ha sido pionera en la regulación de espacios de uso público (Bannen, 1993). Con el fin de dar estatus legal a la red de recorridos peatonales sobre lotes privados, ha acuñado el término galería, que recientemente ha sido incorporado a la Ordenanza General' ${ }^{7}$. Providencia también se destaca por hacer uso de la servidumbre de tránsito para ganar espacios y establecer el irrestricto uso público de espacios de propiedad privada, como sucede con el Paseo Las Palmas y el pasaje Magdalena ${ }^{8}$.

Una vez que se hayan estudiado estas formas de caracterizar los espacios de uso público y todas sus transiciones, será necesario integrar los conceptos a la Ordenanza; entonces el desafío será crear directrices precisas para la construcción de secuencias urbanas de lo público. Sólo así podremos contar con normas que velen por el carácter público y por la continuidad de lo público en los espacios de la ciudad. ARq

\section{Bibliografía}

Bannen, Germán. "El comercio en Providencia”. C.A. № 72, Colegio de Arquitectos de Chile A.G., Santiago, 1993, p. 35. / Bahrdt, Hans Paul. Die moderne Grossstadt. Soziologische Überlegungen zum Städtebau. Wegner Verlag, Hamburgo, 1969, pp. 60, 114. / Dubach, Hannes; Kohlbrenner, Urs y Bernhard Schneider de la Comisión del Senado para el desarrollo del Estado y Grupo de trabajo para la Planificación del Estado (AGS). Umweltschutz und Technologie Berlin Stadtentwicklungsplan Öffentlicher Raum (StEP). Materialien, Berlín, 1999. / Gausa Manuel. "Collective Space". The metapolis dictionary of advanced architecture Actar, Barcelona, 2003, p. 561. / Kayden, Jerold y The New York City Department of Planning. Privately owned public space. The New York experience. John Wiley \& Sons, Hoboken, 2000. / Kodal, Kart y Helmut Krämer. Strassenrecht - systematische Darstellung des Rechts der öffentlichen Strassen. Wege und Plätze in der BRD. Editorial C.H. Beck, Munich, 1999, p. 571. / Selle, Klaus. "Öffentlicher Raum- von was ist die Rede?”. Jahrbuch der Stadterneuerung 2001. Beiträge aus Lehre und Forschung an deutschen Hochschulen. Arbeitskreis Stadterneuerung an deutschen Hochschulen und Institut für Stadt - und Regionalplanung TUBerlin, Uni Dortmund TU Hamburg-Harburg, Humboldt Uni Berlin, Berlín, 2001, pp. 27, 29-30. / Sennett, Richard. Verfall und Ende des öffentlichen Lebens. Die Tyrannei der Initimität. Fischer Taschenbuch Verlag, Frankfurt am Main, 1983, p. 19. / Solà -Morales, Manuel. "Espacios públicos y espacios colectivos”. Revista Universitaria № 46. Ediciones Pontificia Universidad Católica de Chile, Santiago, 1994, pp. 38-41. / Weber, Max. Wirtschaft und Gesellschaft. Original de 1922. Mohr Verlag, Tübingen, 1980 


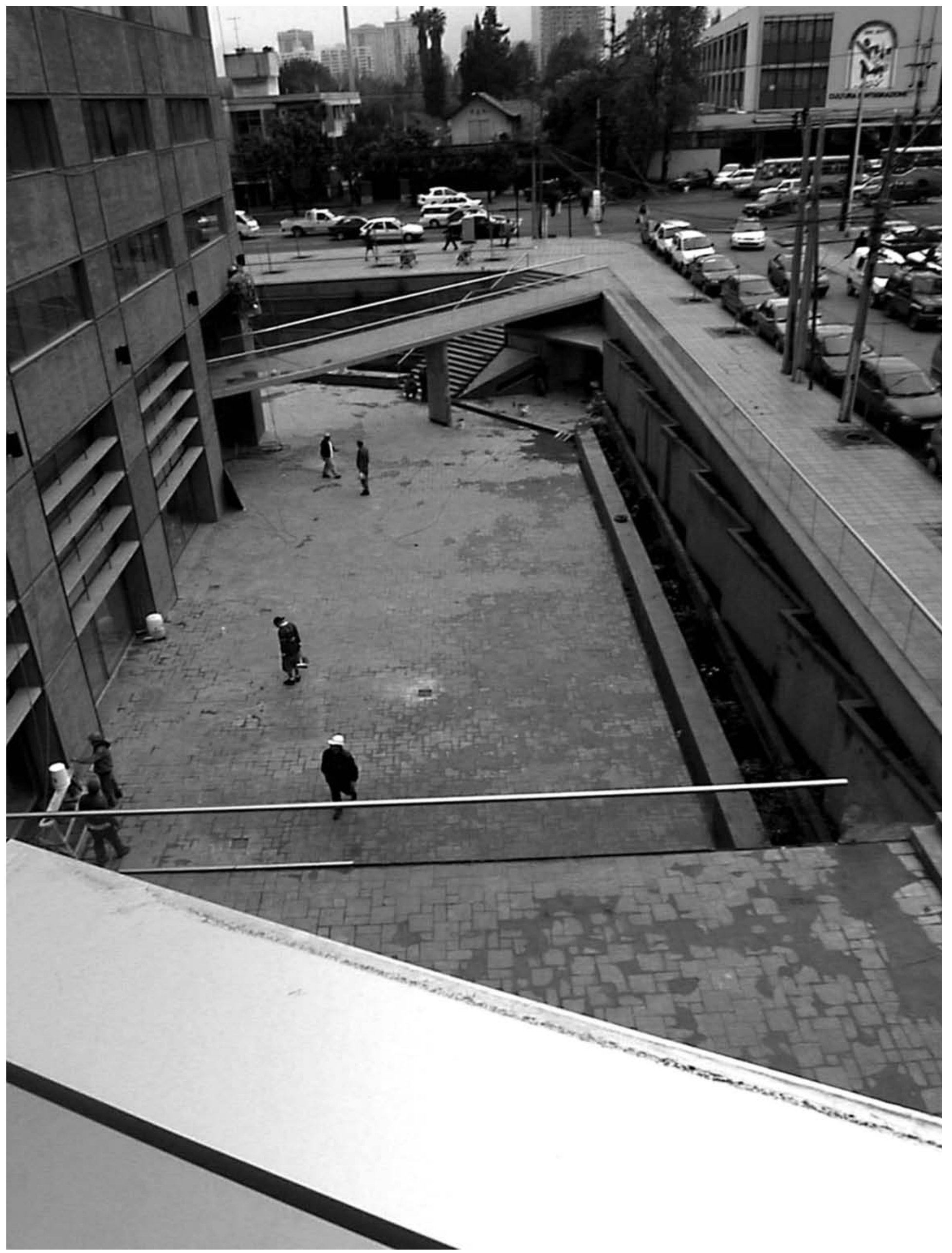

02 Torre Apoquindo, Apoquindo 4775, Las Condes. Fotografía de la autora. 